\title{
Association between income trajectories in childhood and psychiatric disorder: a Swedish population-based study
}

\author{
Emma Björkenstam, ${ }^{1,2}$ Siwei Cheng, ${ }^{3}$ Bo Burström, ${ }^{2}$ Anne R Pebley, ${ }^{1}$ \\ Charlotte Björkenstam, ${ }^{4,5,6}$ Kyriaki Kosidou $^{7,8}$
}

\begin{abstract}
- Additional material is published online only. To view please visit the journal online (http://dx.doi.org/10.1136/ jech-2016-208513).
\end{abstract}

'Department of Community Health Sciences, Fielding School of Public Health and California Center for Population Research, University of California Los Angeles, Los Angeles, California, USA

${ }^{2}$ Division of Social Medicine, Department of Public Health Sciences, Karolinska Institutet, Stockholm, Sweden ${ }^{3}$ Department of Sociology, New York University, New York, New York, USA

${ }^{4}$ Department of Epidemiology, Fielding School of Public Health, University of California, Los Angeles, California, USA ${ }^{5}$ Department of Clinical Neuroscience, Karolinska Institutet, Stockholm, Sweden ${ }^{6}$ Department of Sociology, Stockholm University,

Stockholm, Sweden

${ }^{7}$ Division of Public Health Epidemiology, Department of Public Health Sciences, Karolinska Institutet, Stockholm, Sweden

${ }^{8}$ Center for Epidemiology and Community Medicine, Stockholm County Council Stockholm, Sweden

\section{Correspondence to}

Dr Emma Björkenstam, Division of Social Medicine, Department of Public Health Sciences,

Karolinska Institutet, Stockholm SE-171 77, Sweden; emma.bjorkenstam@ki.se

Received 12 October 2016 Revised 7 February 2017 Accepted 11 February 2017 Published Online First

7 March 2017

\section{CrossMark}

To cite: Björkenstam $\mathrm{E}$

Cheng S, Burström B, et al. J

Epidemiol Community Health 2017:71:648-654.

\section{ABSTRACT}

Background Childhood family income variation is an understudied aspect of households' economic context that may have distinct consequences for children. We identified trajectories of childhood family income over a 12-year period, and examined associations between these trajectories and later psychiatric disorders, among individuals born in Sweden between 1987 and 1991 $(n=534$ 294).

Methods We used annual income data between the ages of 3-14 years and identified 5 trajectories (2 highincome upward, 1 downward and 2 low-income upward trajectories). Psychiatric disorders in the follow-up period after age 15 were defined from International Classification of Disease (ICD)-codes in a nationwide patient register. Multiadjusted risks for all psychiatric disorders, as well as for specific psychiatric diagnoses, were calculated as HRs with $95 \% \mathrm{Cls}$.

Results of the 5 identified income trajectories, the constant low and the downward trajectories were particularly associated with later psychiatric disorder. Children with these trajectories had increased risks for psychiatric disorder, including mood, anxiety, psychotic disorders and attention deficit/hyperactivity disorder. The association remained, even after adjusting for important variables including parental psychiatric disorder. In contrast, the relationship was reversed for eating disorders, for which children in higher income trajectories had elevated risks.

Conclusions Findings show that children growing up in a household characterised by low or decreasing family income have an increased risk for psychiatric disorder. Continued work is needed to reduce socioeconomic inequalities in psychiatric disorders. Policies and interventions for psychiatric disorders should consider the socioeconomic background of the family as an important risk or protective factor.

\section{INTRODUCTION}

The effects of childhood family income on mental health have been well studied, showing associations between economic deprivation in childhood and subsequent mental health morbidity, in childhood, adolescence and adulthood. ${ }^{1-8}$ Studies examining the effect of childhood family income on psychiatric disorder typically conceptualise family income as static, measured as an average across multiple years. Hence, less is known about the association between variation in childhood family income and later psychiatric disorders.

Variation in childhood family income occurs across the income distribution, but is more common and consequential in low-income families. ${ }^{9}$ Until now, only a few studies have examined variation in childhood family income and its association with health and social outcomes. ${ }^{10-12}$ These studies have found unfavourable relationships between childhood family income instability and children's educational attainment, ${ }^{10}{ }^{11}$ development ${ }^{12}$ and behavioural problems. ${ }^{12}$ These studies have mostly focused on income fluctuation in general, but have also suggested that income fluctuations may be particularly harmful among lowincome families. They offer several potential hypotheses through which family income and income variations may affect children's mental health. For example, the family stress model proposes that childhood economic hardship affects children's mental health primarily through its negative effect on parents' increased stress levels, marital conflict and lower parenting quality. ${ }^{1}$ Another pathway, the family investment model, posits that families with greater economic resources are able to make significant investments in their children, whereas disadvantaged families must invest in more immediate family needs. ${ }^{1}$

Furthermore, it has been shown that low-income families tend to have more chaotic and less structured households compared with wealthier families, and theories from developmental psychology and sociology suggest that household chaos and family instability are two aspects of environmental instability that could have consequences for the child's mental health. ${ }^{9}$

There are reasons to believe that income variations are a source of stress for children and parents, particularly in low-income families. ${ }^{10} 12{ }^{13}$ For instance, large swings in income may contribute to more household chaos and family instability, and the effects of income instability may also interact with children's developmental processes. ${ }^{12}$

In our analysis, we characterise childhood family socioeconomic environment by the shape of family income trajectories. We expect that the level and shape of family income trajectories will affect psychiatric well-being. For example, an upward income trajectory indicates an improving economic status, a flat trajectory indicates that economic resources are about the same during all years of the early life course, and a downward trajectory indicates a deteriorating economic status over childhood. We expect children who grew up in families with a flat low-income trajectory to experience persistent disadvantage in their childhood years, and this disadvantage may translate into an increased 
risk of psychiatric disorder in adolescence. ${ }^{1}{ }^{14}$ Moreover, children who grow up with a downward income trajectory will face a deteriorating economic status, which may lead to an intensification of stress and hardship during childhood. This leads us to expect a unique effect of downward income trajectories on later psychiatric outcomes, above and beyond the effects of average income levels.

We capitalised on Sweden's extensive and high-quality registers, by using a large sample of nearly 535000 individuals born between 1987 and 1991. Our aims were to:

1. Identify and describe trajectories of childhood family income over a 12-year period;

2. Describe associations of these trajectories with later psychiatric disorders;

3. Examine whether these associations differ depending on type of psychiatric disorder.

\section{METHODS}

\section{Study population}

The study population was defined as all individuals born in Sweden between 1987 and 1991 ( $n=571$ 797), obtained from the Medical Birth Register. This register contains data on all deliveries in Sweden since $1973 .{ }^{15}$ We excluded children who were adopted $(n=274)$, who emigrated before age 18 years $(n=19398)$ and who died before their 18th birthday $(n=4857)$ because a high proportion of data were missing on important variables. Those with missing or incomplete income information $(n=7576)$ and those whose parents were in the top $1 \%$ income group ( $n=5398)$ were also excluded, to avoid the possible influence of a few extremely high-income outliers. Our final analytical sample comprised 534294 individuals. The unique Swedish personal identity number was used to link this cohort to multiple healthcare and administrative registers as described below.

The Causes of Death Register comprises information on all deaths of Swedish residents since 1952. The National Patient Register (NPR) includes all individuals admitted to psychiatric or general hospitals, with complete coverage for all inpatient care since 1987 and outpatient care since 2001. The Total Enumeration Income Survey contains data on income and on governmental benefits provided to all Swedish residents. The Total Population Register includes information on age, sex, place of residence and other relevant demographic characteristics. The Longitudinal Integration Database for Health Insurance and Labor Market Studies integrates existing data from the labour market, educational and social sectors. Families were linked through the Multi-Generation register, which contains all known relationships between children and parents (born in 1932 or later) since 1961.

\section{Childhood family income}

Family income for each year from age 3 years until age 14 years was obtained by calculating the sum of all the family members' incomes, minus taxes plus transfers. Weights were used to adjust for household composition and size. ${ }^{16}$ Income was adjusted for inflation to values in 1999 according to Statistics Sweden's consumer price index, and also log transformed to adjust for positive skewness. ${ }^{17}$

\section{Psychiatric outcomes}

The study population was prospectively followed because they were diagnosed with a psychiatric disorder after age 15 years (from 2002 if born 1987, and from 2006 if born 1991)-from the time of diagnosis until, at maximum, 31 December 2011. Psychiatric disorder was defined as receiving a psychiatric diagnosis (International Classification of Disease (ICD-10) codes F00-F99) during psychiatric inpatient or outpatient care, as recorded in the NPR. Additionally, the following types of disorders were analysed separately: substance misuse (ICD-10: F10-F19); psychotic disorders (ICD-10: F20-F29); mood disorders (ICD-10: F30-F39); anxiety, dissociative, stress-related and somatoform disorders (ICD-10: F40-F48); eating disorders (ICD-10: F50); and attention deficit/hyperactivity disorder (ADHD; ICD-10: F90).

\section{Covariates}

All analyses were adjusted for sex and birth year. Owing to known associations between immigrant status (including second generation) and mental health in the Swedish population, ${ }^{18}$ we adjusted for whether the mother was born in Sweden or not. Since income has been positively associated with parental psychiatric disorder ${ }^{13}$ and parental psychiatric disorder is a risk factor for children's psychopathology, ${ }^{19}$ we controlled for parental psychiatric disorder, defined as at least one parent treated in inpatient or outpatient care with a psychiatric diagnosis (ICD-9: 290-319; ICD-10: F00-F99) during the time income was captured. We also controlled for factors that may affect both family income and psychiatric disorder, such as the mother's age at the child's birth, and parental educational attainment. Highest parental education was defined as the attained educational level when the child was 15 years old, and classified as: (1) 9 years of compulsory school or less, (2) $10-12$ years of education and $(3) \geq 13$ years of education. Since single-parent household is associated with both the childhood family income and psychiatric disorder, ${ }^{20-22}$ we also controlled for whether or not the child was living in a single-parent household during all the years income was captured. Finally, childhood psychopathology before age 15 years was defined as having had a psychiatric inpatient or outpatient contact before age 15 .

\section{Statistical analyses}

Group-based trajectory modelling was used to identify income trajectories when the child was between 3 and 14 years of age. We used the Stata command traj, which is based on a mixture model. This model provides the capacity to identify subgroups of individuals who followed distinct trajectories during the time of observation and estimates a regression model for each discrete group, instead of just an overall average. ${ }^{23}$ Group member probabilities are estimated by a multinomial logit function. We started by identifying the model with the optimal number of subgroups by estimating models with one to six subgroups using the normal distribution (CNORM). ${ }^{25}$ The model for the 12-year period that best fitted the data was determined by the Bayesian information criterion (BIC). The lowest BIC value (closest to zero) indicates the model that best fits the data. The final number of trajectories was established when sequential comparisons of the BIC between models yielded no further substantial reductions in the BIC score.

Second, we estimated associations between each trajectory group and later psychiatric disorder. We followed the study participants from age 15 to first psychiatric contact, or to the end of observation on 31 December 2011. We performed multivariate analyses using Cox hazards models, and calculated HRs with 95\% CIs. Five regression models were examined: model I adjusted for sex and birth year. Model II was further adjusted for foreign-born mother, mother's age at child's birth, parental education and single-parent household. In model III, we added adjustments for parental psychiatric disorder, whereas model IV 
included income level (log-transformed average income). Finally, all variables were included in model $\mathrm{V}$. We also estimated associations between childhood family income trajectory group and specific psychiatric diagnoses in young adulthood, using the five models described above

Sensitivity analysis: In order to examine the effect of childhood family income on adult onset psychiatric disorder, we stratified the cohort into two groups by history of childhood psychopathology and repeated the analyses.

Statistical analyses were conducted using SAS V.9.4 and Stata V.13.

\section{Ethics statement}

The study population was based on linkage of several public national registers. Ethical review is always required when using register data in Sweden. The ethical review is performed by regional ethical review boards and the risk appraisal associated with the Law on Public Disclosure and Secrecy is conducted by data owners. The ethical review boards can waive the usual requirement to obtain informed consent directly from the data participants (or in case of minors/children the next of kin, carers or guardians) and will often do so if the research is supported by the ethical review board and the data have already been collected in some other context.

\section{RESULTS}

On the basis of the BIC results, five trajectory groups were included in the analysis (figure 1). The traj command provides individual fit estimates, that is, the probabilities that each individual belongs to their assigned trajectory group. The average probability for members of a trajectory group should be $\geq 0.7$ to $0.8 .^{26}$ All identified groups had averages above 0.90 , indicating a very good fit. The five trajectory groups displayed heterogeneity in childhood family income variations (figure 2 and online supplementary figure S1). For all but one trajectory group, the family income increased slightly over the studied period. We labelled the five trajectory groups as 'highest income trajectory' (13\%), 'second highest income trajectory' (41\%), 'second lowest income trajectory' (21\%), 'downward income trajectory' (13\%) and 'lowest income trajectory' (12\%).

Table 1 presents descriptive statistics and rates of psychiatric disorder for the study population by trajectory group. The cohort was evenly distributed between women and men (49\% vs $51 \%$ ). The highest income trajectory was characterised by individuals whose parents were born in Sweden and had higher levels of education. These individuals generally grew up with both parents, and had mothers who were slightly older than the other trajectory groups. In the lowest income trajectory, onefifth of the individuals had a foreign-born parent. Parental psychiatric disorder was more common in this group $(20 \%$ compared with $10 \%$ in the total population) and children were more likely to grow up in a single-parent household.

In total, 66946 individuals (13\%) were diagnosed with a psychiatric disorder during follow-up (table 1). The most common disorders were anxiety spectrum disorders, mood disorders and substance misuse. With the exception of eating disorders, those in the highest income trajectory group had the lowest proportions of all studied psychiatric outcomes, whereas those in the lowest income trajectory had the highest proportions.

Compared with individuals in the highest income trajectory group, all other groups had an increased risk for psychiatric disorder (table 2). For example, children with slightly lower levels of family income (but an upward trajectory) had higher risks for

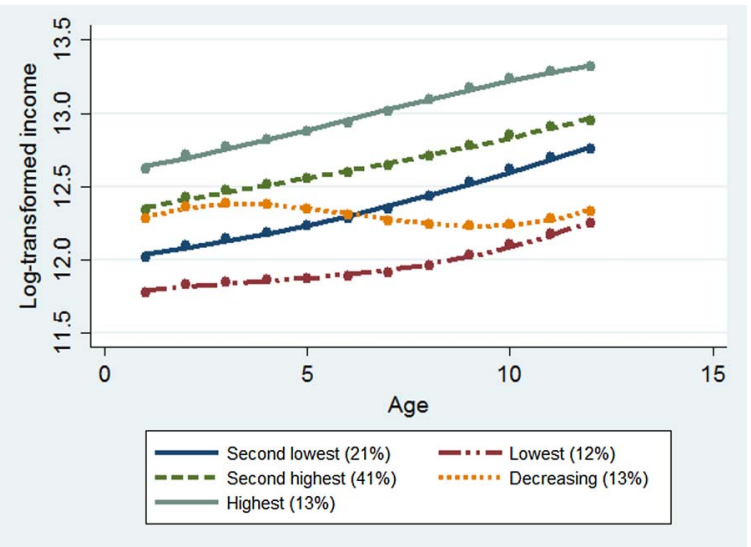

Figure 2 The five trajectory groups of childhood family income (between the ages of 3 and 14 years). Income is log transformed (y-axis).
Figure 1 Number of trajectory groups (1-6; x-axis) and their Bayesian information criterion values (y-axis).

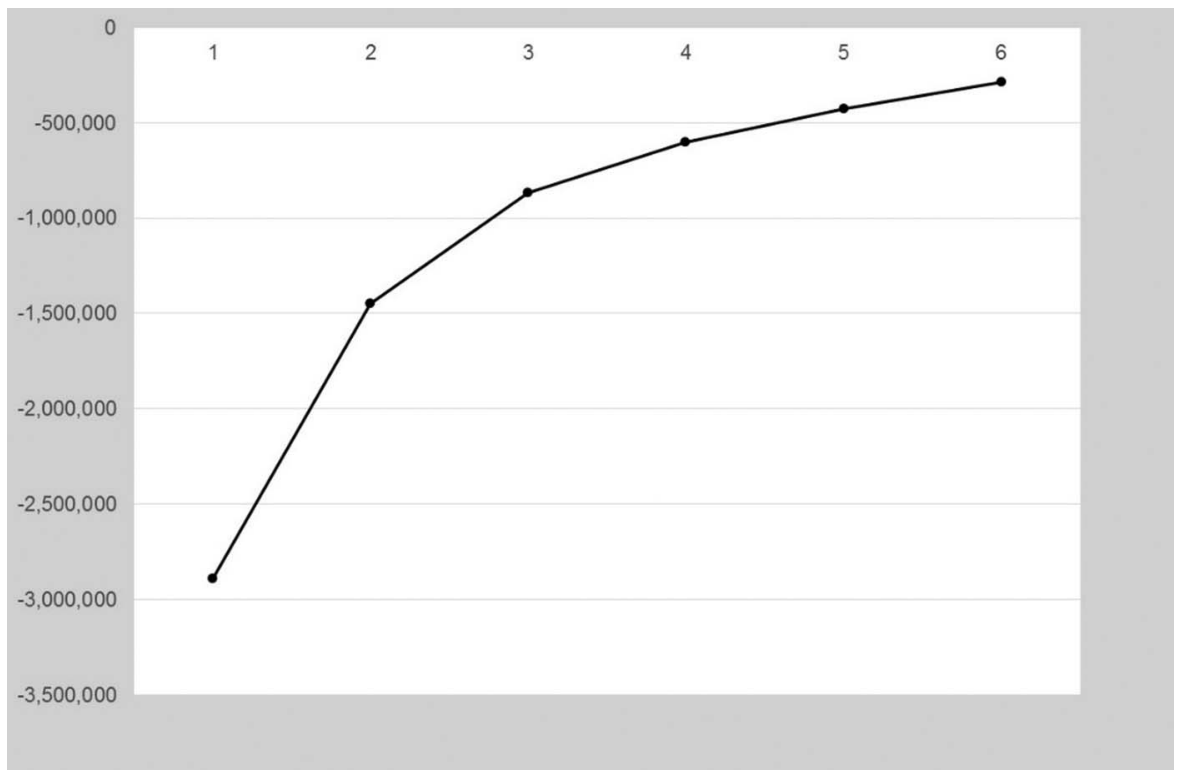


Table 1 Sociodemographic characteristics and psychiatric outcomes, by childhood family income trajectory group

\begin{tabular}{|c|c|c|c|c|c|c|c|}
\hline Characteristics & Total & $\begin{array}{l}\text { Highest income } \\
\text { trajectory }\end{array}$ & $\begin{array}{l}\text { Second highest } \\
\text { income trajectory }\end{array}$ & $\begin{array}{l}\text { Second lowest } \\
\text { income trajectory }\end{array}$ & $\begin{array}{l}\text { Downward } \\
\text { income trajectory }\end{array}$ & $\begin{array}{l}\text { Lowest income } \\
\text { trajectory }\end{array}$ & $\begin{array}{l}\text { p Value } \\
\left(\chi^{2}\right)^{*}\end{array}$ \\
\hline All & 534294 & 70745 & 221445 & 110733 & 67484 & 63887 & \\
\hline Average income in Swedish Krona (SD) & $294405(92733)$ & 463678 (72 335) & $322055(32745)$ & $245950(25171)$ & 228656 (29 412) & $164560(22816)$ & \\
\hline \multicolumn{8}{|l|}{ Sex } \\
\hline Women & $259968(49 \%)$ & $34427(49 \%)$ & $107433(49 \%)$ & $53881(49 \%)$ & $33124(49 \%)$ & $31103(49 \%)$ & 0.15 \\
\hline Men & $274326(51 \%)$ & $36318(51 \%)$ & $114012(51 \%)$ & $56852(51 \%)$ & $34360(51 \%)$ & $32784(51 \%)$ & \\
\hline Foreign-born biological mother & $59013(11 \%)$ & $5194(7 \%)$ & $18513(8 \%)$ & $15767(14 \%)$ & $8145(12 \%)$ & $11394(18 \%)$ & $<0.01$ \\
\hline Parental psychiatric disorder & $50796(10 \%)$ & 2901 (4) & $12982(6)$ & $11706(11)$ & $10418(15)$ & $12789(20)$ & $<0.01$ \\
\hline Mother's age at child's birth (mean, SD) & $28.5(5.1)$ & $31.5(4.4)$ & $28.8(4.7)$ & $27.1(5.0)$ & $28.4(5.1)$ & $26.9(5.6)$ & \\
\hline \multicolumn{8}{|l|}{ Highest parental educational attainment } \\
\hline $0-9$ years & $27357(5 \%)$ & $944(1 \%)$ & $7911(4 \%)$ & $7668(7 \%)$ & $4377(6 \%)$ & $6457(10 \%)$ & $<0.01$ \\
\hline $10-12$ years & $272976(51 \%)$ & $14851(21 \%)$ & $109642(50 \%)$ & $68091(61 \%)$ & $40138(59 \%)$ & $40254(63 \%)$ & \\
\hline $13+$ years & $233812(44 \%)$ & $54941(78 \%)$ & $103864(47 \%)$ & $34945(32 \%)$ & $22935(34 \%)$ & $17127(27 \%)$ & \\
\hline Missing & $149(<0.5 \%)$ & $9(<0.5 \%)$ & $28(<0.5 \%)$ & $29(<0.5 \%)$ & $34(<0.5 \%)$ & $49(<0.5 \%)$ & \\
\hline Single-parent household all years & $32557(6 \%)$ & $115(<0.5 \%)$ & $1082(<0.5 \%)$ & $6424(6 \%)$ & $3355(5 \%)$ & $21581(34 \%)$ & $<0.01$ \\
\hline \multicolumn{8}{|l|}{ Psychiatric outcomes } \\
\hline $\begin{array}{l}\text { Any psychiatric diagnosis before age } \\
15 \text { years }\end{array}$ & $17273(3 \%)$ & $1759(2 \%)$ & $5985(3 \%)$ & $3739(3 \%)$ & $2758(4 \%)$ & $3032(5 \%)$ & $<0.01$ \\
\hline $\begin{array}{l}\text { Any psychiatric diagnosis after age } \\
15 \text { years }\end{array}$ & $66946(13 \%)$ & $6589(9 \%)$ & $22787(10 \%)$ & $14920(13 \%)$ & $10790(16 \%)$ & $11860(19 \%)$ & $<0.01$ \\
\hline Substance misuse & $19573(4 \%)$ & $1783(3 \%)$ & $6140(3 \%)$ & $4327(4 \%)$ & $3374(5 \%)$ & $3949(6 \%)$ & $<0.01$ \\
\hline Psychotic disorders & $1802(<0.5 \%)$ & $142(<0.5 \%)$ & $586(<0.5 \%)$ & $407(<0.5 \%)$ & $309(0 \%)$ & $358(1 \%)$ & $<0.01$ \\
\hline Mood disorders & $20433(4 \%)$ & $1971(3 \%)$ & $7004(3 \%)$ & $4521(4 \%)$ & $3357(5 \%)$ & $3580(6 \%)$ & $<0.01$ \\
\hline Anxiety spectrum disorders & $26432(5 \%)$ & $2298(3 \%)$ & $8756(4 \%)$ & $5917(5 \%)$ & $4480(7 \%)$ & $4981(8 \%)$ & $<0.01$ \\
\hline Eating disorders & $5061(1 \%)$ & $871(1 \%)$ & $2044(1 \%)$ & $962(1 \%)$ & $627(1 \%)$ & $557(1 \%)$ & $<0.01$ \\
\hline ADHD & $9299(2 \%)$ & $714(1 \%)$ & $2862(1 \%)$ & $2228(2 \%)$ & $1557(2 \%)$ & $1938(3 \%)$ & $<0.01$ \\
\hline
\end{tabular}

${ }^{*}$ Statistical significance evaluated by $\chi^{2}$ tests.

ADHD, attention deficit/hyperactivity disorder.

psychiatric disorder. The risk increased further in a graded manner for each trajectory group, with the highest HRs observed in the lowest income trajectory (HR 2.1, 95\% CI 2.0 to 2.1). In the second model, the HRs decreased slightly. When adjustments were made for income level (model IV), all HRs decreased markedly. In the fully adjusted model (model V), all but one trajectory group (second highest) remained significantly associated with psychiatric disorder.

Lower income trajectories predicted each type of psychiatric disorders, with the exception of eating disorder (table 2). Compared with the highest income trajectory, children in the lowest income trajectory group had the highest HRs, followed by those in the downward income trajectory. Although the second lowest income trajectory and decreasing trajectory groups have a very similar average income, the downward income trajectory has a greater HR for psychiatric outcomes than the second lowest income trajectory group. This result demonstrates that measuring income trajectories has an advantage over the traditionally used average income measure. Highest risk estimates were observed for ADHD. In contrast, eating disorder was more common in the highest income trajectory HR of 1.4 (95\% CI 1.3 to 1.6), when compared with the lowest income trajectory.

Our sensitivity analyses revealed that study participants without childhood psychopathology in the low-income and downward income trajectory groups experienced increased risk of psychiatric disorder. In contrast, history of childhood psychopathology yielded similar risks for early adulthood psychiatric disorder regardless of trajectory group (sensitivity analyses, online supplementary table S1).

\section{DISCUSSION}

\section{Key findings}

In this study, we used a large cohort of 534294 individuals to identify trajectories of childhood family income over a 12 -year period, and to examine associations of these trajectories with early adulthood psychiatric disorders. We identified two income trajectory groups that were strongly associated with psychiatric disorder: one low-income (but upward) trajectory and one downward income trajectory. Children assigned to these trajectories had increased risks for several different types of psychiatric disorder. The association remained, even after adjusting for important variables including parental psychiatric disorder and even if we limited the sample to individuals without childhood psychopathology. In contrast, the relationship was reverse for eating disorders-children in higher income groups had the greatest risks.

The finding that children in the lowest income trajectory had a markedly increased risk for early adulthood psychiatric disorder confirms previous associations found between childhood economic disadvantage and psychiatric disorder, ${ }^{5} 121327$ especially among children living in poverty. ${ }^{28} 29$ Families in this group had annual mean incomes below the European Union's (EU) definition of relative poverty as an income below $60 \%$ of the median. ${ }^{30}$ Thus, these are particularly poor families, at least within the EU context.

Our study extends earlier findings by demonstrating an association between declining childhood family income and later psychiatric disorder. Children who grew up in a household characterised by a downward income trajectory had the second highest risk for later psychiatric disorder. One prior study 
Table 2 Associations between childhood family income trajectory and psychiatric outcomes from age 15 years

\begin{tabular}{|c|c|c|c|c|}
\hline \multirow[b]{2}{*}{ Psychiatric disorder } & \multicolumn{4}{|l|}{ Income trajectory } \\
\hline & $\begin{array}{l}\text { Second highest } \\
\text { income trajectory }\end{array}$ & $\begin{array}{l}\text { Second lowest } \\
\text { income trajectory }\end{array}$ & $\begin{array}{l}\text { Downward income } \\
\text { trajectory }\end{array}$ & $\begin{array}{l}\text { Lowest income } \\
\text { trajectory }\end{array}$ \\
\hline \multicolumn{5}{|l|}{ Any psychiatric disorder } \\
\hline Model I* & 1.1 (1.1 to 1.1$)$ & 1.5 (1.4 to 1.5$)$ & 1.8 (1.7 to 1.8$)$ & 2.1 (2.0 to 2.1 ) \\
\hline Model IIt & $1.1(1.0$ to 1.1$)$ & 1.3 (1.3 to 1.4$)$ & 1.6 (1.6 to 1.7$)$ & 1.8 (1.7 to 1.8$)$ \\
\hline Model IIIF & 1.1 (1.1 to 1.1$)$ & 1.4 (1.3 to 1.4$)$ & 1.6 (1.6 to 1.7$)$ & 1.8 (1.8 to 1.9$)$ \\
\hline Model IV§ & $0.9(0.9$ to 1.0$)$ & 1.1 (1.0 to 1.2$)$ & $1.3(1.2$ to 1.3$)$ & $1.3(1.2$ to 1.4$)$ \\
\hline Model Vף & $1.0(0.9$ to 1.0$)$ & $1.1(1.1$ to 1.2$)$ & $1.3(1.2$ to 1.4$)$ & 1.3 (1.2 to 1.4$)$ \\
\hline \multicolumn{5}{|l|}{ Substance misuse } \\
\hline Model I* & 1.1 (1.0 to 1.2$)$ & 1.5 (1.5 to 1.6$)$ & $2.0(1.9$ to 2.1$)$ & 2.5 (2.4 to 2.7$)$ \\
\hline Model IIt & $1.0(0.9$ to 1.0$)$ & 1.3 (1.2 to 1.3$)$ & 1.7 (1.6 to 1.8$)$ & 1.8 (1.6 to 1.9$)$ \\
\hline Model III‡ & 1.1 (1.0 to 1.1$)$ & $1.5(1.4$ to 1.5$)$ & $1.8(1.7$ to 1.9$)$ & 2.2 (2.1 to 2.3 ) \\
\hline Model IV§ & $0.9(0.9$ to 1.0$)$ & $1.2(1.1$ to 1.3$)$ & 1.5 (1.4 to 1.7$)$ & $1.6(1.4$ to 1.9$)$ \\
\hline Model Vף & $1.0(0.9$ to 1.0$)$ & $1.2(1.1$ to 1.3$)$ & 1.5 (1.4 to 1.7$)$ & 1.6 (1.4 to 1.8$)$ \\
\hline \multicolumn{5}{|l|}{ Psychotic disorders } \\
\hline Model I* & $1.2(1.0$ to 1.5$)$ & $1.7(1.4$ to 2.0$)$ & 2.2 (1.8 to 2.6$)$ & 2.6 (2.1 to 3.2 ) \\
\hline Model IIt & 1.4 (1.1 to 1.6$)$ & 1.8 (1.5 to 2.2$)$ & 2.3 (1.9 to 2.9$)$ & 2.7 (2.2 to 3.3 ) \\
\hline Model III‡ & $1.2(1.0$ to 1.5$)$ & $1.5(1.3$ to 1.9$)$ & 1.9 (1.6 to 2.3$)$ & 2.2 (1.8 to 2.7$)$ \\
\hline Model IV§ & 0.9 (0.8 to 1.2$)$ & 1.0 (0.8 to 1.4$)$ & 1.2 (0.9 to 1.7$)$ & 1.2 (0.7 to 1.8$)$ \\
\hline Model Vף & 1.0 (0.8 to 1.3$)$ & 1.1 (0.8 to 1.5$)$ & 1.3 (0.9 to 1.8 ) & 1.2 (0.7 to 1.8$)$ \\
\hline \multicolumn{5}{|l|}{ Mood disorders } \\
\hline Model I* & 1.1 (1.1 to 1.2$)$ & $1.4(1.3$ to 1.5$)$ & $1.8(1.7$ to 1.9$)$ & 2.0 (1.9 to 2.1$)$ \\
\hline Model IIt & 1.1 (1.0 to 1.2$)$ & 1.3 (1.3 to 1.4$)$ & $1.6(1.5$ to 1.7$)$ & 1.7 (1.6 to 1.8$)$ \\
\hline Model III‡ & $1.1(1.0$ to 1.1$)$ & $1.3(1.2$ to 1.4$)$ & $1.6(1.5$ to 1.7$)$ & 1.7 (1.6 to 1.8$)$ \\
\hline Model IV§ & $0.9(0.9$ to 1.0$)$ & 1.1 (1.0 to 1.2$)$ & $1.3(1.2$ to 1.4$)$ & $1.3(1.1$ to 1.5$)$ \\
\hline Model Vף & $1.0(0.9$ to 1.1$)$ & 1.1 (1.0 to 1.2$)$ & $1.3(1.2$ to 1.4$)$ & $1.2(1.1$ to 1.4$)$ \\
\hline \multicolumn{5}{|c|}{ Anxiety spectrum disorders } \\
\hline Model I* & $1.2(1.1$ to 1.2$)$ & $1.6(1.5$ to 1.7$)$ & $2.0(1.9$ to 2.1$)$ & 2.4 (2.3 to 2.5$)$ \\
\hline Model II $†$ & $1.2(1.1$ to 1.2$)$ & 1.5 (1.4 to 1.6$)$ & $1.9(1.8$ to 2.0$)$ & 2.1 (2.0 to 2.2 ) \\
\hline Model III‡ & $1.2(1.1$ to 1.2$)$ & 1.5 (1.4 to 1.6$)$ & $1.8(1.7$ to 1.9$)$ & 2.1 (2.0 to 2.2 ) \\
\hline Model IV§ & $1.0(0.9$ to 1.0$)$ & 1.1 (1.0 to 1.2$)$ & $1.3(1.2$ to 1.5$)$ & $1.3(1.2$ to 1.5$)$ \\
\hline Model Vף & $1.0(0.9$ to 1.1$)$ & 1.1 (1.0 to 1.2$)$ & $1.3(1.2$ to 1.5$)$ & $1.3(1.1$ to 1.4$)$ \\
\hline \multicolumn{5}{|l|}{ Eating disorders } \\
\hline Model I* & 0.7 (0.7 to 0.8$)$ & 0.7 (0.6 to 0.8$)$ & 0.7 (0.7 to 0.8$)$ & 0.7 (0.6 to 0.8$)$ \\
\hline Model II & $0.9(0.8$ to 0.9$)$ & $0.9(0.8$ to 1.0$)$ & $0.9(0.8$ to 1.0$)$ & $0.9(0.8$ to 1.0$)$ \\
\hline Model III‡ & 0.7 (0.7 to 0.8$)$ & 0.7 (0.6 to 0.7$)$ & 0.7 (0.6 to 0.8$)$ & 0.7 (0.6 to 0.7$)$ \\
\hline Model IV§ & 0.8 (0.7 to 0.9$)$ & $0.8(0.7$ to 1.0$)$ & 0.9 (0.8 to 1.1$)$ & $1.0(0.7$ to 1.2$)$ \\
\hline Model Vף & $0.9(0.8$ to 1.0 & $0.9(0.8$ to 1.1$)$ & $0.9(0.8$ to 1.1$)$ & $0.9(0.7$ to 1.2$)$ \\
\hline \multicolumn{5}{|l|}{ ADHD } \\
\hline Model I* & $1.4(1.2$ to 1.5$)$ & 2.3 (2.1 to 2.5$)$ & 2.6 (2.3 to 2.8$)$ & 3.5 (3.2 to 3.8 ) \\
\hline Model IIt & 1.1 (1.0 to 1.2$)$ & 1.7 (1.6 to 1.9$)$ & 2.0 (1.9 to 2.2$)$ & 2.3 (2.1 to 2.6$)$ \\
\hline Model III‡ & $1.3(1.2$ to 1.4$)$ & 2.1 (1.9 to 2.3$)$ & 2.2 (2.1 to 2.5$)$ & 2.9 (2.7 to 3.2$)$ \\
\hline Model IV§ & $1.0(0.9$ to 1.1$)$ & $1.3(1.2$ to 1.5$)$ & $1.4(1.2$ to 1.6$)$ & 1.5 (1.2 to 1.8$)$ \\
\hline Model Vף & 1.0 (0.9 to 1.1$)$ & 1.2 (1.1 to 1.4$)$ & 1.4 (1.2 to 1.6$)$ & 1.3 (1.1 to 1.6$)$ \\
\hline \multicolumn{5}{|c|}{$\begin{array}{l}\text { HR with } 95 \% \text { Cls. } \\
\text { Reference group: highest income trajectory. } \\
\text { *Adjusted for sex and birth year. } \\
\text { tModel I with additional adjustments for foreign-born mother, mother's age at child's birth, parental education and single-parent household. } \\
\text { †Model I with additional adjustments for parental psychiatric disorder. } \\
\text { \&Model I with additional adjustments for overall average income. } \\
\text { TModels I-IV. }\end{array}$} \\
\hline
\end{tabular}

examining effects of changes in household income on child mental health showed that income decline was detrimental to later psychiatric disorder. ${ }^{27}$ However, this study specifically examined child depression and antisocial behaviour and did not investigate whether the effects persisted into late adolescence and early adulthood. A recent review of socioeconomic inequalities in child and adolescent mental health revealed a similar pattern, where decline in childhood socioeconomic status (SES) was associated with increased mental health problems. ${ }^{4}$

Furthermore, our large cohort enabled us to examine differential effects of childhood income trajectory by type of psychiatric disorders. Low and declining childhood family income appeared to increase the risk of ADHD, substance misuse and psychosis in particular. The association remained, even after 
adjusting for parental psychiatric disorder, one of the major confounders of parental SES and children's mental health problems. ${ }^{4}$ The association was reversed for eating disorders, where the risks were increased in children in the highest income trajectories. This finding is in line with prior studies demonstrating higher rates of eating disorders in children from higher socioeconomic backgrounds. ${ }^{31} 32$

When adjusting for parental psychiatric morbidity, the HRs were only slightly reduced. On the other hand, the HRs decreased markedly when adjusting for income level, suggesting that the overall level of income is more important than the shape of the trajectory for the higher income trajectory groups. However, our findings suggest that even after controlling for the overall income level, there is still a substantial effect of the shape of the trajectories, and this effect is no less than the estimated effects of other relevant family-level variables such as foreign-born parent and parental education. Hence, our study highlights the importance of considering the dynamic nature of childhood family income, above and beyond the average income, in the association between childhood family income and early adulthood mental health.

Several mechanisms explaining these associations have been suggested. ${ }^{19} 121428$ Family financial hardship is intertwined in a complex manner with several co-factors, such as parenting quality, family structure and parent psychological factors, all of which may affect children's mental health. ${ }^{28}$ Furthermore, economic deprivation in early life has been shown to have longterm effects on children's stress responsivity that may partly explain our findings. ${ }^{5} 121333$ Some studies suggest that the association between low childhood family income, or income instability, and psychiatric disorder is mediated by parental investment and family processes. ${ }^{1} 1213$ On the basis of our results, parental psychiatric morbidity seems to play a minor role in the relationship between childhood family income trajectory and psychiatric disorder. In contrast, average income played a more important role. These findings indicate support for the family investment model rather than the family stress model.

Our findings have important implications for mental health interventions targeting children growing up in economic deprivation. Strategies are needed, both to reduce socioeconomic inequalities and to improve the mental health of disadvantaged children. For example, comprehensive early childhood programmes for children at risk have been shown to have extended benefits over time. ${ }^{34}$ School plays an important role, because economic deprivation has a strong impact on children's educational achievement, ${ }^{103536}$ and programmes aiming to improve cognitive and academic outcomes have been shown to be beneficial for children's mental health. ${ }^{34}$ Thus, future efforts to prevent or mitigate the negative effects of childhood economic deprivation on psychiatric disorder may benefit from integration of strategies that improve school performance among vulnerable youth.

This study has several methodological strengths, including the longitudinal population-based design, the use of national registers with a high rate of completeness and no loss to follow-up. The large cohort size also allows for detailed analyses on specific types of psychiatric disorder. Other quantitative studies with similar design and research questions, but with other data sources, often struggle with insufficient power and missing data.

This study also has some methodological weaknesses. With respect to treatment-seeking, we do not know whether the associations between childhood family income and psychiatric disorder vary between those who seek treatment and those who do not. It has been shown that socioeconomic factors play a part in treatment-seeking, ${ }^{37}$ even in Sweden which has universal access to healthcare. This is also true for psychiatric disorder and treatment: disadvantaged socioeconomic background is a risk factor for most psychiatric disorders and predicts higher mental health service use, ${ }^{37}$ probably due to the higher psychiatric morbidity in this population. If the associations between childhood family income and psychiatric disorder vary among those who seek treatment and those who do not, our results may be biased. However, this bias would affect any other study relying on psychiatric diagnosis and treatment as an outcome. With respect to follow-up, the youngest individuals were followed until age 20 years and the oldest until age 24 years. Although many psychiatric disorders are known to have their onset in adolescence, certain disorders including psychosis typically have later onsets. ${ }^{38}$ Thus, the younger birth cohorts may include individuals who have not yet received a diagnosis, although they in fact suffer from a psychiatric disorder. This potential outcome misclassification would lead to underestimation of the true risk. Finally, we did not fully take into account the effect of timevarying control variables, including single-parent household and parental psychiatric disorder.

\section{CONCLUSION}

The results presented in this study show that children growing up in households with low (but increasing) or declining family incomes have an increased risk for early adulthood psychiatric disorder. Comparison studies of income inequalities in health have shown that they are particularly low in the Scandinavian countries including Sweden. ${ }^{39} 40$ Sweden has a very low per cent of child poverty according to the Unicef comparisons. ${ }^{30}$ However, not all children in Sweden fare equally well. Children in financially vulnerable families have increased risk for later negative health and social outcomes, ${ }^{41}{ }^{42}$ which has also been demonstrated in this study. Finally, these findings emphasise the importance of policy measures to enable children to grow up in a stable and safe financial environment.

\section{What is already known on this subject}

Former studies have demonstrated an association between childhood family income levels and mental health. Despite earlier findings, childhood family income variation is an understudied aspect of households' economic context that may have distinct consequences for children.

\section{What this study adds}

Our study expands this literature in an important way by providing longitudinal evidence that children growing up in a household characterised by low or declining family income have an increased risk for psychiatric disorder in late adolescence and early adulthood.

Contributors EB, SC and ARP originated the idea. EB and SC analysed the data. $E B$ wrote the manuscript draft. All authors contributed to the interpretation of the results and to the writing of the final article.

Funding This study was supported by a grant from the Swedish Society for Medical Research (CB), Swedish Council for Working Life and Social Research (grant number 2013-2729, EB). 
Competing interests None declared.

Ethics approval This project has been reviewed and approved by the Regional Ethical Review Board of Karolinska Institutet, Stockholm, Sweden (dnrs: 2010/ 1185-31/1 and 2013/1118-32).

Provenance and peer review Not commissioned; externally peer reviewed.

\section{REFERENCES}

1 Conger RD, Donnellan MB. An interactionist perspective on the socioeconomic context of human development. Annu Rev Psychol 2007;58:175-99.

2 Eamon MK, Zuehl RM. Maternal depression and physical punishment as mediators of the effect of poverty on socioemotional problems of children in single-mother families. Am J Orthopsychiatry 2001;71:218-26.

3 McLaughlin KA, Breslau J, Green JG, et al. Childhood socio-economic status and the onset, persistence, and severity of DSM-IV mental disorders in a US national sample. Soc Sci Med 2011;73:1088-96.

4 Reiss F. Socioeconomic inequalities and mental health problems in children and adolescents: a systematic review. Soc Sci Med 2013;90:24-31.

5 Shapero BG, Steinberg L. Emotional reactivity and exposure to household stress in childhood predict psychological problems in adolescence. J Youth Adolesc 2013;42:1573-82.

6 Gilman SE, Kawachi I, Fitzmaurice GM, et al. Socio-economic status, family disruption and residential stability in childhood: relation to onset, recurrence and remission of major depression. Psychol Med 2003;33:1341-55.

7 Kuh D, Power C, Blane D, et al. Socioeconomic pathways between childhood and adult health. In: Kuh D, Ben-Shlomo Y, eds. A life course approach to chronic disease epidemiology. Oxford: Oxford University Press, 2004.

8 Wadsworth M, Butterworth S. Early life. In: Marmot M, Wilkinson R, eds. Social determinants of health. UK: Oxford University Press, 2006.

9 Ackerman BP, Kogos J, Youngstrom E, et al. Family instability and the problem behaviors of children from economically disadvantaged families. Dev Psychol 1999;35:258-68.

10 Gennetian LA, Wolf S, Hill HD, et al. Intrayear household income dynamics and adolescent school behavior. Demography 2015;52:455-83.

11 Hardy BL. Childhood income volatility and adult outcomes. Demography 2014;51:1641-65.

12 Hill HD, Morris PA, Gennetian LA, et al. The consequences of income instability for children's well-being. Child Dev Perspect 2013;7:85-90.

13 Yeung WJ, Linver MR, Brooks-Gunn J. How money matters for young children's development: parental investment and family processes. Child Dev 2002;73: 1861-79.

14 Duncan GJ, Brooks-Gunn J. Consequences of growing up poor. New York: Russell Sage Foundation, 1997

15 Cnattingius S, Ericson A, Gunnarskog J, et al. A quality study of a medical birth registry. Scand J Soc Med 1990;18:143-8.

16 Statistics Sweden. Longitudinal integration database for health insurance and labou market studies (LISA by Swedish acronym). Retrieved 08/10/2016. http://www.scb. se/en_/Services/Guidance-for-researchers-and-universities/SCB-Data/Longitudinalintegration-database-for-health-insurance-and-labour-market-studies-LISA-bySwedish-acronym/

17 Cheng S. A Life Course Trajectory Framework for understanding the intracohort pattern of wage inequality. AJS 2014;120:633-700.

18 Kosidou K, Hellner-Gumpert C, Fredlund P, et al. Immigration, transition into adult life and social adversity in relation to psychological distress and suicide attempts among young adults. PLOS ONE 2012;7:e46284.
19 Siegenthaler E, Munder T, Egger M. Effect of preventive interventions in mentally ill parents on the mental health of the offspring: systematic review and meta-analysis. J Am Acad Child Adolesc Psychiatry 2012;51:8-17 e8.

20 Weitoft GR, Hjern A, Haglund B, et al. Mortality, severe morbidity, and injury in children living with single parents in Sweden: a population-based study. Lancet 2003;361:289-95.

21 McLanahan S, Sandefur G. Growing up with a single parent: what hurts, what helps. Cambridge, MA: Harvard University Press, 1994

22 Daryanani I, Hamilton J, Abramson L, et al. Single mother parenting and adolescent psychopathology. J Abnorm Child Psychol 2016;44:1411-23.

23 Jones B, Nagin D. A note on a stata plugin for estimating group-based trajectory models. Sociol Methods Res 2013;42:608-13.

24 Jones B, Nagin D, Roeder K. A SAS procedure based on mixture models for estimating developmental trajectories. Sociol Methods Res 2001;29:374-93.

25 Jones B, Nagin D. A Stata Plugin for Estimating Group-Based Trajectory Models. Retrieved 08/12/2016. http://ssrc.indiana.edu/seminars/wimdocs/2013-03-29_ nagin trajectory stata-plugin-info.pdf.

26 Cote $\bar{S}$, Tremblay RE, Nagin $D$, et al. The development of impulsivity, fearfulness, and helpfulness during childhood: patterns of consistency and change in the trajectories of boys and girls. J Child Psychol Psychiatry 2002;43:609-18.

27 Strohschein L. Household income histories and child mental health trajectories. J Health Soc Behav 2005;46:359-75.

28 Yoshikawa H, Aber JL, Beardslee WR. The effects of poverty on the mental, emotional, and behavioral health of children and youth: implications for prevention. Am Psychol 2012;67:272-84

29 Costello EJ, Compton SN, Keeler G, et al. Relationships between poverty and psychopathology: a natural experiment. JAMA 2003;290:2023-9.

30 UNICEF. Measuring Child Poverty. Italy 2012. Retrieved 10/12/2016. https://www. unicef-irc.org/publications/pdf/rc10_eng.pdf

31 Ahren JC, Chiesa F, Af Klinteberg B, et al. Psychosocial determinants and family background in anorexia nervosa - results from the Stockholm Birth Cohort Study. Int J Eat Disord 2012;45:362-9.

32 Godart N, Legleye S, Huas C, et al. Epidemiology of anorexia nervosa in a French community-based sample of 39,542 adolescents. Open J Epidemiol 2013;3:53-61.

33 Duncan G, Yeung W, Brooks-Gunn J, et al. How much does childhood poverty affect the life chances of children? Am Sociol Rev 1998;63:406-23.

34 Aber L, Morris P, Raver C. Children, families and poverty: definitions, trends, emerging science and implications for policy. Soc Policy Rep Soc Res Child Dev 2012;26:1-28.

35 Montez JK, Hayward MD. Cumulative childhood adversity, educational attainment, and active life expectancy among U.S. adults. Demography 2014;51:413-35.

36 Sirin S. Socioeconomic status and academic achievement: a meta-analytic review of research. Rev Educ Res 2005;75:417-53.

37 Kosidou K, Dalman C, Lundberg M, et al. Socioeconomic status and risk of psychological distress and depression in the Stockholm Public Health Cohort: a population-based study. J Affect Disord 2011:134:160-7.

38 Kessler RC, Amminger GP, Aguilar-Gaxiola S, et al. Age of onset of mental disorders: a review of recent literature. Curr Opin Psychiatry 2007:20:359-64.

39 OECD. Divided We Stand. Why Inequality Keeps Rising. 2011. Retrieved on 10/12/ 2016. http://www.oecd.org/els/soc/dividedwestandwhyinequalitykeepsrising.htm.

40 van Doorslaer $E$, Wagstaff $A$, Bleichrodt $H$, et al. Income-related inequalities in health: some international comparisons. J Health Econ 1997;16:93-112.

41 Ringbäck Weitoft G, Hjern A, Batljan I, et al. Health and social outcomes among children in low-income families and families receiving social assistance-a Swedish national cohort study. Soc Sci Med 2008:66:14-30.

42 Vinnerljung B, Hjern A, Ringbäck-Weitoft G, et al. Children and young people at risk. Social Report 2006. Int J Soc Welfare 2007:16:163-202. 